\title{
Shotcrete: early strength and re-entry revisited - practices and technology
}

\author{
M Rispin Normet Group, Switzerland \\ OB Kleven Normet Group, Norway \\ R Dimmock Normet Group, UK \\ R Myrdal Normet International Ltd, Switzerland
}

Shotcrete, a globally employed support system of choice in underground mining, is required to perform its support function not only over the expected life of underground openings, but also from a safety and productivity perspective, at a very early age. The balance between placement ability, early strength and long-term performance is a delicate one which has been repeatedly improved upon as shotcrete has proliferated in mining and tunnelling. Early strength is particularly important in safeguarding the integrity of underground openings and the people and machinery which need to return to them as quickly as safety doctrine allows.

This paper covers the state-of-the-art with respect to practices and technology which forms the basis for the safest, earliest re-entry policies. Technologies discussed include the examination of strength development via thermal imagery, infrared analysis, fibre performance, admixture and accelerator formulation, and robotic placement. Practices discussed cover approaches in both mining and tunnelling, early re-entry times and policies, and lessons learned anecdotally from contemporary case studies.

Preservation of people and assets, the environment and cost savings are co-drivers of industry advances.

Keywords: shotcrete, early strength, re-entry, set accelerator, infrared analysis, fibre, tunnelling

\section{Introduction}

Shotcrete, a proven and versatile ground support tool for underground mines, has a widespread application around the globe today. It has proliferated over the last 25-30 years due to advances in technology, improvements in application and practice, acknowledgement at large in the industry of its unique support capabilities, and a proven, attractive cost/performance ratio. While dry-spray application does and will continue to exist in ever-decreasing quantities, the development of shotcrete has been focused around the wet-spray method.

This paper will focus exclusively on the wet-spray method and cover a historical review of the evolution of re-entry practices, cite recent case study approaches to the issue, benchmark practices in the tunnelling industry, and cover a variety of technologies which can aid and abet speed of re-entry.

Some of the highlights include a means by which thermal imagery can prove the quality enhancements of early strength development via the use of a purpose-designed, low-pulsation sprayed concrete pump; unique, state-of-the-art admixture technology; and a recent study result which suggests that macrosynthetic fibre reinforcement can offer an advantage over steel fibre in early age shotcrete toughness.

While the rate of introduction of advancements in wet shotcrete technology has been declining over the last decade compared to earlier, there nevertheless have been significant steps forward which contribute to the attractiveness of shotcrete in mining, as well as a continuous effort to make the ground support more economical and effective. The resultant proliferation of shotcrete use has created something of a virtuous circle, in the sense that as more operations adopt it and learn from it, more advances are driven forward, and the industry demand for ever-improving early strength development and re-entry times has deepened. 


\section{$2 \quad$ Shotcrete in mining}

Shotcrete is multi-faceted and has found favour in underground mining for a variety of reasons. It provides rapid, full areal support, thereby holding up large as well as small blocks of ground. It can be rapidly applied: a $5 \mathrm{~m}$ wide $\times 5 \mathrm{~m}$ high $\times 5 \mathrm{~m}$ round advance is typically fully covered in under $25 \mathrm{~min}$ while miners remain under supported ground (Rispin et al. 2013). In situ, it is a remarkably durable support and, in static conditions, can provide service over the life of an installation. While relatively brittle, and therefore not able to withstand sustained movement, its toughness performance is greatly improved with the addition of reinforcement. The typical reinforcement technique in mining began with wire mesh and has evolved over the last 20 years through steel fibre to the current, popular use of macro-synthetic fibre.

The actual, complete support mechanism of shotcrete is still not fully understood today but remains largely accepted as an active support system (Dimmock et al. 2003) due to its capability of providing resistance to movement with its penetration of naturally occurring cracks in the substrate. Reinforced shotcrete provides toughness against failure in punching shear, diagonal shear, compression and tension (Rispin et al. 2003).

As today's underground mines move deeper and into more challenging ground conditions, shotcrete remains a widely adopted component of a typical support system. In particular, caving mines will use reinforced shotcrete as initial, rapid support (Rispin et al. 2013) supplemented with other reinforcement measures in the interest of providing a strong, static system, but also one which can absorb large amounts of energy and behave in a ductile, durable manner.

The efficiency and attractiveness of shotcrete in an underground mine is heavily influenced by logistics: getting quality wet shotcrete to the working face. The logistics system involves a combination of fixed installation and mobile equipment and, depending upon the needs of the operation, there exists a variety of permutations and combinations to suit the purpose. For flatter, shallower orebodies with ramp access, specifically designed transmixers or agitators are almost exclusively the means of choice. For deeper and more steeply dipping orebodies, a dedicated borehole (or slickline) - or potentially one shared with backfill transfer - is the preferred infrastructure (Rispin et al. 2009).

As with any ground support method or element of mining, cost is a consideration. While it will vary from mine to mine, and is also subject to the vagaries of cost accounting methods (a challenging concept in looking at any specific underground mining process), it can be estimated that an 'all in' ballpark cost for

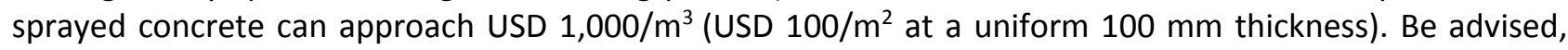
this includes material costs, reinforcement (excluding macro-synthetic fibres), production, all logistics both lateral and vertical, manpower, equipment, maintenance, training, supervision, waste, etc. The above all-in cost can realistically be targeted to approach or drop below USD $800 / \mathrm{m}^{3}$ (Rispin et al. 2013).

The importance of strength development is underpinned by the need for the shotcrete to:

- Support its own applied weight.

- Hold blocks in place in the early stages of excavation (ground support philosophy has taught us that keeping small blocks in place can keep the larger ones in place).

- Provide a supported environment which permits equipment and subsequently miners to safely return to the workspace.

Early age strength development considers measurements above $0.5 \mathrm{MPa}$ and those recorded up to $24 \mathrm{hrs}$ of age (Dimmock et al. 2003).

\section{Early re-entry in mining}

The early, past norm for re-entry into a shotcreted heading was in the 8-18 hr range. The standard was very conservative, by today's measures, and reflective of the immaturity of understanding of the method's performance characteristics. As the parameters of shotcrete became more wisely understood, the re-entry time for standard shotcreted headings moved in many mines to eight hours. That standard moved lower to 
four hours and eventually two hours (Dimmock et al. 2003). This progression came as the result of a combination of ground support theory and empirical progressions, and included a maturation of concrete strength development measurement methods.

Ultimately, it is the mine's ground control engineer who will determine what compressive strength is required to provide a safe re-entry time policy for the mine based on anticipated and observed ground conditions. This compressive strength is a key performance indicator of the shotcrete's toughness, its ability to resist falls of ground due to the various failure mechanisms referenced earlier.

Today, the industry norm for re-entry under 'typical' ground conditions (if such a thing can exist in such a globally diverse industry) is the assurance of reaching $1 \mathrm{MPa}$ compressive strength. This is a standard that was being strived for some 15 years ago (Dimmock et al. 2003; Rispin et al. 2003) and is in more widespread application today. Today, this threshold is typically reached within 30-120 min, depending on many factors including concrete raw material selection, mix design (including the important water/cementitious ratio), spraying equipment selection and application technique, and temperature.

Technology has been a major driver in the ability of shotcrete to develop that critical early strength without impinging on its ultimate strength, or the continuous rate of strength development. Correspondingly, achieving the 'best' early strength is not a safety or performance success unless the shotcrete maintains a steady strength development without enduring a dormant period, and without sacrificing final performance which is needed in the long-term. The more recent technology contributions to this phenomenon are presented in the ensuing sections.

The baseline practices for successful early strength development and consequently early re-entry policies have been well documented (Rispin et al. 2003). At the same time, new analyses and test results have, in the relatively recent past, emerged and some significant developments are described here.

\section{$4 \quad$ State-of-the-art technology}

As known to all, chemical admixtures and accelerators play key roles in sprayed concrete technology. The workability and fluidity of the fresh concrete, as well as the setting and hardening behaviour of the sprayed concrete, are all parameters easily affected by chemical additives.

\subsection{Plasticisers and superplasticisers}

In order to keep the water/cement ratio at an acceptable low level - to take advantage of the corresponding high concrete strength gain - it is crucial to use a water reduction admixture. However, the classic lignosulphonate-based water reducer will certainly slow down the early age strength development of the sprayed concrete. Lignosulphonates contain sugar, which is an extremely efficient set retarder. When this was discovered decades ago, melamine and naphthalene-based superplasticisers were introduced. Later, it was found that even these superplasticisers were not optimal with respect to early strength development.

A common characteristic of these traditional plasticisers/superplasticisers is that they are all by-products (even waste materials) from chemical industry. Approximately 20 years ago a new class of superplasticisers was introduced, and today this type is the preferred superplasticiser for sprayed concrete. There is a wide range of them - characterised as co-polymers based on polycarboxylate ethers (PCEs) - and they are tailormade for concrete. The water reduction capacity, slump retention property, etc. may vary considerably within this product group. The dispersion of cement grains is obtained by the so-called 'steric hindrance mechanism' caused by the adsorbed polymers on the cement grain surface rather than by 'electrostatic repulsion', which is the dominating mechanism by which melamines and naphthalenes act (Ohta et al. 1997). In addition to the positive effect on fresh concrete rheology and workability, PCE-based superplasticisers have only a minor, if any, negative effect on early age strength of sprayed concrete. It has been reported that up to a $40 \%$ increase in early age strength (one hour after spraying) can be achieved when using a PCE-based superplasticiser instead of a naphthalene based superplasticiser (Myrdal 1999). However, the choice of superplasticisers does not affect final strength. 


\subsection{Hydration control admixtures}

It is very important to be able to maintain the flow and workability of the concrete over longer periods of time before the actual spraying. Ideally, the fresh concrete workability should be unaffected, and no setting occurs until the cement hydration is activated by the accelerator in the nozzle of the sprayer. A common set retarder for concrete - typically based on sodium gluconate, a sugar-like chemical - is not the right choice for this application, but instead a hydration control admixture should be used. However, to distinguish between the different performances of the two types is not straightforward. Laboratory tests where retarded/hydration-controlled mortars have been accelerated by using state-of-the-art alkali-free accelerators have shown that a gluconate-based retarder may seem to act as well as a hydration control admixture at the same equimolar dosages (Myrdal \& Griffith 2014a):

- Similar slump retention.

- Similar initial and final set times when accelerated by the alkali-free accelerator.

- No significant difference in strength development of an accelerated mortar when measured from 2 hrs curing onwards.

Despite this fact, it has been demonstrated that there is a noticeable difference between the two retarders when you spray the concrete, especially the first few minutes after spraying. A spray test comparing a common concrete retarder (gluconate) with a modern hydration control admixture (TamCem HCA) - at equimolar dosages - showed that the compressive strength $5 \mathrm{~min}$ after spraying increased from $0.23 \mathrm{MPa}$ when using a sodium gluconate retarder to $0.36 \pm 0.03 \mathrm{MPa}$ when using TamCem HCA (Myrdal \& Griffith 2014a). This clearly demonstrates the unique performance of HCA over gluconates and the need to do spray trials when developing admixtures for sprayed concrete. The reason for the discrepancy between cast laboratory samples and sprayed concrete is not yet fully understood, but is thought to have to do with the way the accelerator is mixed into the concrete.

The next step in this technology has been to develop a new hydration control admixture incorporating a dormant/secondary accelerator. The accelerator part is awakened in the nozzle of the sprayer when the concrete is mixed with the alkali-free accelerator. This idea was already discussed many years ago (Myrdal et al. 2001), and has now been commercialised (and patented) by Normet International Ltd. This product (TamCem HCA Plus) is able to boost the early age strength development of the sprayed concrete to new heights. The spray test described included the performance of HCA Plus, and the comparison of gluconate, HCA and HCA Plus (all at equal set retarding dosages) was done with the concrete mix design shown in Table 1. The compressive strength values five minutes after spraying were obtained using a penetration needle according to BS EN 14488-2 (British Standards Institution 2006). The early age strength values are shown in Table 2.

Table 1 Sprayed concrete mix design (water/cement $=0.40)$

\begin{tabular}{ll}
\hline Constituent & Amount $\left(\mathbf{k g} / \mathbf{m}^{3}\right)$ \\
\hline Cement (CEM II/A-V 52.5N) & 500 \\
Sand (0-8 mm) & 1,573 \\
Water & 200 \\
Superplasticiser (TamCem 60) & 3.5 \\
Gluconate retarder/TamCem HCA/TamCem HCA Plus & $1.0 / 1.0 / 5.0^{*}$ \\
Alkali-free accelerator (TamShot 90AF, 8\% by weight of cement) & 40 \\
\hline
\end{tabular}

$* 5.0=1.0$ (the retarder part) +4.0 (the secondary accelerator part). 
Table 2 Compressive strength values five minutes after spraying (BS EN 14488-2 (British Standards Institution 2006))

\begin{tabular}{ll}
\hline Type of retarder/hydration control & Compressive strength (MPa) \\
\hline Sodium gluconate & $0.23 \pm 0.02$ \\
TamCem HCA & $0.36 \pm 0.03$ \\
TamCem HCA Plus & $0.55 \pm 0.04$ \\
\hline
\end{tabular}

\subsection{Accelerators for sprayed concrete}

There is a wide range of chemicals capable of shortening the setting time and/or speeding up the rate of cement hydration when added to concrete. Many of these chemicals are also relevant for sprayed concrete. The classic accelerators for sprayed concrete have been water soluble silicates (typically sodium silicate, or 'waterglass') and water soluble aluminates (typically sodium aluminate).

Soluble sodium silicate provides rapid setting by reaction with calcium in the cement paste to form solid calcium silicate: Na-silicate (soluble) $+\mathrm{Ca}^{2+}$ (dissolved in fresh concrete) $\rightarrow$ Ca-silicate (insoluble) $+\mathrm{Na}^{+}$.

With time the precipitate will form a hydrated calcium silicate gel somewhat similar to that formed by the hydration of $\mathrm{C}_{3} \mathrm{~S} / \mathrm{C}_{2} \mathrm{~S}$ clinkers in the cement. Sodium silicate is still used in sprayed concrete technology, and is characterised by (Prudêncio 1998; Rixom \& Mailvaganam 1999):

- Compatibility with most cements.

- Relatively low early strengths.

- Reduced final strength at high dosages.

Sodium aluminates are far more alkaline than sodium silicates. These are highly caustic solutions which require caution in handling. Alkali aluminates react with several components in the cement (sulphate, calcium and $\mathrm{C}_{3} \mathrm{~A}$ ) to form ettringite and calcium aluminate hydrates and possibly other compounds. Issues related to sodium aluminate accelerators are:

- Health hazards associated with handling of highly caustic materials (a significant safety risk in underground mining).

- Addition of a lot of alkalis and the risk of promotion of alkali-aggregate reactions.

- Decrease in final strength.

These issues led to the development of non-alkaline accelerators (often referred to as alkali-free accelerators). They are all weakly acidic $(\mathrm{pH} \sim 2-4)$ with aluminium sulphate as the main constituent (Bürge 2001), and typically formulated with additional non-disclosed constituents. A screening of the patent literature and the product data sheets from suppliers of alkali-free accelerators has shown that the typical ingredients found in these products are (Myrdal 2011):

- Aluminium sulphate.

- Aluminium hydroxide.

- Alkanolamine, e.g. DEA.

- Organic acids, e.g. formic acid.

- Fluorides.

Some of these alkali-free accelerators are transparent low-viscous aqueous solutions (all chemicals dissolved), whilst others are more viscous dispersions of tiny particles. 
The flash setting behaviour of alkali-free accelerators is mainly caused by the reaction of aluminum sulphate with the lime in the cement forming ettrigite, and then the following strength development is partly caused by the aluminium sulphate and partly by the additional constituents. Current research and development activities are focusing mostly on the latter part. One major challenge is the introduction of blended cements (typically 20\% fly ash replacement of Portland cement clinker). Some of these cements develop strength quite slowly, therefore a specific ('tailor-made') accelerator is needed. One example of an accelerator developed to handle blended cements is TamShot 110AF.

\subsection{Beyond state-of-the-art technology}

The state-of-the-art technology described previously in this paper will certainly last for many more years, but new innovative ideas related to sprayed concrete are seen. There are some emerging challenges or opportunities in the coming years:

- Development of sulphate-free accelerators.

- Further early age performance of fibre reinforced sprayed concrete.

- Development of Portland cement-free sprayed concrete.

The alkali-free accelerators on the market today were developed partly due to the risk of alkaline accelerators promoting detrimental alkali-aggregate reactions. Questions have been raised - based on laboratory tests - whether the high content of sulphate in alkali-free accelerators in the long run may promote an internal form of sulphate attack in the concrete (Paglia et al. 2003; Lee et al. 2009). However, no conclusive results have yet been found in the field. Anyway, this uncertainty should/will call for an attempt to develop sulphate-free or low-sulphate accelerators. Initial screening of sulphate-free accelerating chemicals has been carried out, but with no breakthrough yet (Myrdal 2012).

Fibres were introduced in sprayed concrete in Norway in the late 1970s with the incorporation of steel fibres into the sprayed concrete mix. In the latter part of the 1990s, macro-synthetic fibres were introduced to the market, and hybrid mixes (a 50/50 blend of steel and macro-synthetic fibres) were used. Subsequently, macro-synthetic fibres have been widely used in both mining and tunnelling. Macro-synthetic fibres have an undesirable side-effect related to the density of the fibres below 1.0 in that they float on water. This has caused problems with fibres blocking dewatering pumps and other issues. Due to the environmental issues with fibres from rebound in the muck from the concrete spraying, macro-fibres have been avoided for use in certain projects in Norway, for example. This has triggered the development of fibres from other, emerging materials like basalt.

The focus on ductility performance of fibre-reinforced sprayed concrete has been almost exclusively at 28 days and to a lesser extent at seven days. Very recently, investigation on the behaviour at a very early age (within a few hours after application) has begun. This is because there is reason to believe that the performance of fibres can play a significant role at an early age when ground load may be at its peak.

There are a few challenging issues related to Portland cement, e.g. $\mathrm{CO}_{2}$ emission during manufacturing, mechanical properties (e.g. low tensile strength, porosity) and durability (e.g. lack of fire resistance and chemical resistance). Some of these issues might be solved if a geopolymer binder could replace Portland cement in sprayed concrete. However, pure geopolymers need thermal curing to gain acceptable early age strength. Therefore, geopolymer concrete has typically found its application within the precast industry. If wider applications of geopolymer concrete are to be developed, the engineering properties, particularly in terms of setting time and strength gain at ambient temperatures, need to be improved. An attempt to develop a setting and hardening accelerator for geopolymer concrete cured at room temperature started three years ago (Myrdal \& Griffith 2014b). Table 3 shows a fly ash-based geopolymer mortar mix design, and Table 4 shows the strength development of this mortar with and without an accelerating admixture at high dosage ( $10 \%$ by weight of fly ash). It is seen that the early age strength can be exceptionally high, even when cured at ambient temperature. Preliminary tests, not yet published, have shown that these accelerated mortars are very resistant to fire attack $\left(>1,000^{\circ} \mathrm{C}\right)$ and acidic attack $(10 \%$ sulphuric acid). 
Table 3 Geopolymer mortar mix design (Myrdal \& Griffith 2014b)

\begin{tabular}{ll}
\hline Constituent & Amount (g) \\
\hline Standard sand (EM 196-1) & 1,350 \\
Low-calcium fly ash (type F) & 450 \\
Sodium silicate, $\mathrm{SiO}_{2} / \mathrm{Na}_{2} \mathrm{O}$ molar ratio $3.25,38 \%$ solution & 126 \\
Sodium hydroxide, 45\% solution, $16.6 \mathrm{M} \mathrm{NaOH}$ & 54 \\
Water & 25 \\
Superplasticiser, TamCem 11, 42\% solution & 2 \\
Accelerator, 10\% by weight of fly ash & 45 \\
\hline
\end{tabular}

Table 4 Compressive strength of geopolymer mortar cured at $20^{\circ} \mathrm{C}$ (Myrdal \& Griffith 2014b)

\begin{tabular}{lll}
\hline Time & Non-accelerated mortar (MPa) & Accelerated mortar (MPa) \\
\hline $1 \mathrm{hr}$ & - & $2.0 \pm 0.2$ \\
$3 \mathrm{hrs}$ & - & $5.1 \pm 0.3$ \\
$24 \mathrm{hrs}$ & - & $8.8 \pm 0.3$ \\
4 days & 2.33 & $11.9 \pm 0.5$ \\
7 days & 7.82 & $13.2 \pm 0.5$ \\
\hline
\end{tabular}

\section{$5 \quad$ Potential in transferring tunnelling best practice}

Depending on which underground industry you work in, or what mining school or education you received, the argument for whether there is a dominant transfer of technology between mining and tunnelling or vice versa is always an enthusiastic discussion. The authors, however, perceive there are considerable potential benefits to adopt new tunnelling industry shotcrete technologies, but also acknowledge the need to review and implement new design/rock support concepts for increased productivity and safety. Some of the more relevant tunnelling technologies and rock support concepts are highlighted in Section 5.1, and are considered to quite easily be transferred to most mining shotcreting processes.

\subsection{Enhanced control of quality and costs}

One of the more recent steps forward in shotcreting technology has been to produce homogeneous permanent sprayed concrete for tunnel linings. This has been achieved by reducing the pulsation at the spraying nozzle and easing the task of spraying with robotic manipulators:

- The development of highly workable low water/cement wet mix concrete (flows in excess of $600 \mathrm{~mm}$ ), typically stabilised up to $10 \mathrm{hrs}$ using hydration control admixtures. These mixes allow the two shotcrete pump cylinders to be as close to $100 \%$ filled as possible, reducing gaps in the concrete pumping.

- The use of alkali-free set accelerators that support early age strength and long-term strength characteristics, but also reduce aggregate/fibre rebound and dust generation during spraying processes.

- The development of computer-controlled hydraulics to independently control the variable speed of the pump cylinders and the change-over between each cylinder to the smallest time interval possible. 
- The reduction of pulsation in set accelerator supply to the nozzle by using continuous flow mono pumps using integrated computer-controlled dosing systems to match the concrete pump output.

- The choice of adequately sized air compressors to ensure no losses of air volume and pressure occur at the nozzle and to produce the required velocity of the sprayed concrete out of the nozzle for proper compaction on the substrate.

- More advanced PC controlled hydraulic systems on spraying robots to allow the shotcrete operator a more intuitive feel when spraying and for the boom to have smoother movements in what is described as semi-automatic spraying mode.

The aforementioned technologies are typical features of modern spraying equipment for both, mines and tunnels, and the concrete technology will reduce the cost of wastage, reduce the fall-outs from the roof sections, and ensure the rock mechanics ground support parameters are met, particularly with structural fibre energy absorption and shotcrete compressive strength (Figure 1). The safety of the mine operation is more assured as the rock support performance is much less variable, which is certainly necessary for earlier re-entry strategies based on compressive strength gain, and the spraying environment for the operatives is improved.

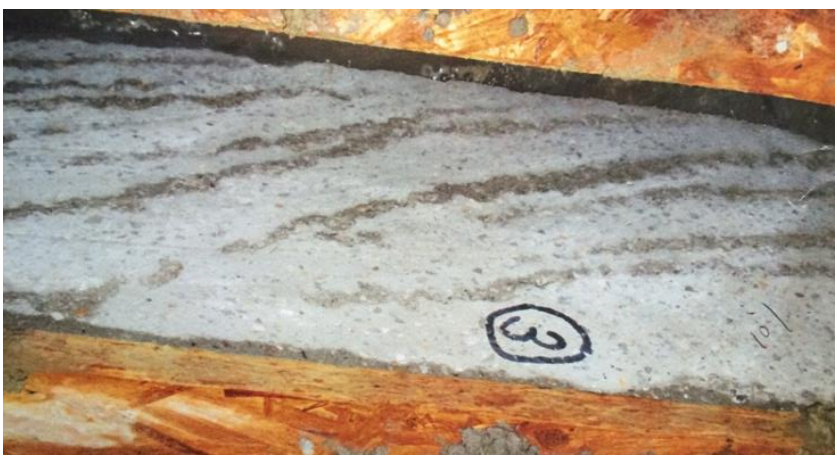

(a)

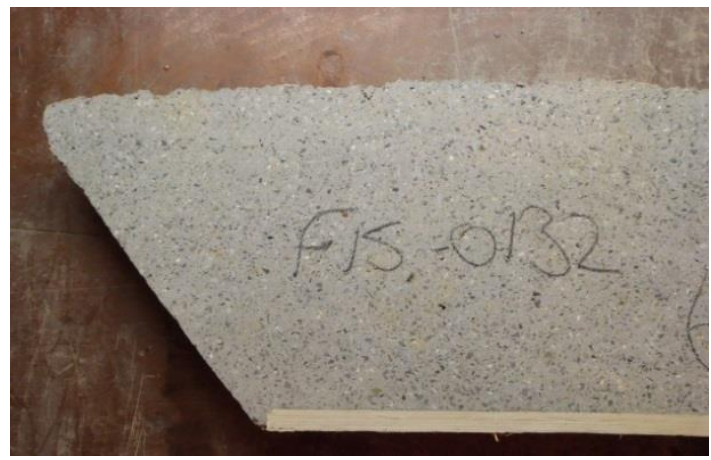

(b)

Figure 1 (a) Shotcrete produced through standard shotcrete pumps with pulsation; and, (b) Latest technology shotcrete pumps with minimal pulsation

In parallel to the PC-controlled systems on the spraying robots, this has allowed machine producers to further develop and offer mine owners real time monitoring of their sprayed concrete operations. However, recently the trend, certainly in tunnelling projects where daily control is a focus, is that the analysis of the machine data is now being achieved either by USB download from the machine or, in more advanced projects, via real-time data transfer by wireless local area networks in the mine or tunnel project as indicated in Figure 2. As with all monitoring systems, the value to the process comes from processing the data to enable informed decisions to be made to improve the shotcrete process underground.

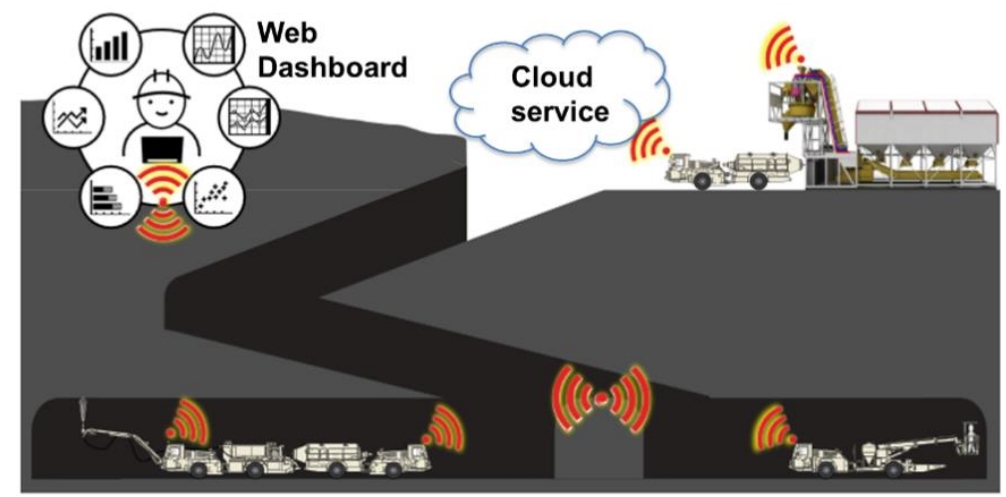

Figure 2 Underground machines linked to wireless local area networks underground are becoming state-of-the-art and viable for relaying real-time data on shotcrete, and other processes 
As shown in Figure 3,Figure modern data collection systems and sensors on shotcrete pumps and robotic sprayers present the miner with cylinder filling percentage, cement content of mix and pre-set dosages of set accelerator that he can select from the spraying remote control or screen. Figure 3 is a screenshot of the last spraying process event. The chart shows the actual set accelerator dosage over time for two machines in the mine, spraying the same mix. This type of data is very valuable in terms of potential cost savings as one spraying rig with its crew are applying shotcrete at $8 \%$ say, whilst the other spraying rig is applying it at $6.5 \%$. This draws the mine management to steer the accelerator consumption in the correct target level of $6 \%$ average with resultant savings in the range of $25-30 \%$.
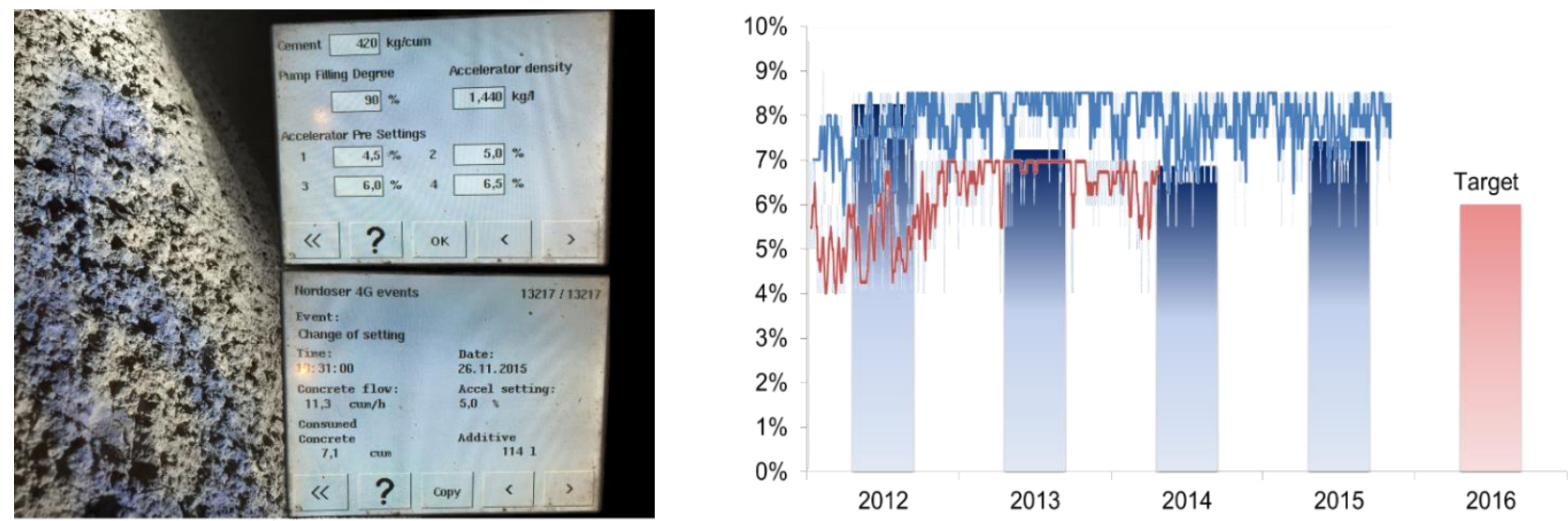

Figure 3 (a) Typical on-board computer displays showing recent and current activities; and, (b) Downloaded data of set accelerator percentage dosage over time

\subsection{Safe, improved re-entry time}

Productivity is a key success driver for any mine, as it is with tunnelling projects, based on the familiar expression 'time is money'. The tunnelling industry has been particularly focused on early age strength development for the last 15 years, and the Austrian Concrete Society developed three classes of early age strength development referred to as $J_{1}, J_{2}$ and $J_{3}$ which are now adopted into the Euronorm BS EN 14488-2 (British Standards Institution 2006). These strength classes were developed to ensure the correct performance of the shotcrete for different conditions. So $J_{1}$ is a low-strength development and is suitable for slopes and shafts, $J_{2}$ is for most tunnelling applications where thick layers can be built safely overhead and is typically specified for most projects in soft ground. Finally $J_{3}$ is for very rapid strength development for running ground conditions or higher than normal water ingress, etc. Quite often $\mathrm{J}_{2}$ is modified so that more performance is specified particularly in high-value urban tunnelling projects in soft ground where settlement control is required, coupled with the necessity of fast-thick linings constructed with high-output spraying robots. Whilst the main driver for these early age strength classes like $J_{2}$ drive towards a safe underground construction approach, they have a useful benefit of allowing faster construction or, in the case of mining, faster re-entry times assuming the rock conditions and installation of other support measures (such as rockbolts) allow.

The current, widely adopted method of early age shotcrete strength measurement is shown in Figure 4, where penetration resistance and pull-out resistance are indirect, calibrated means of determining early age strength. The Euronorm BS EN 14488-2 (British Standards Institution 2006) describes the measurement methods in full. 

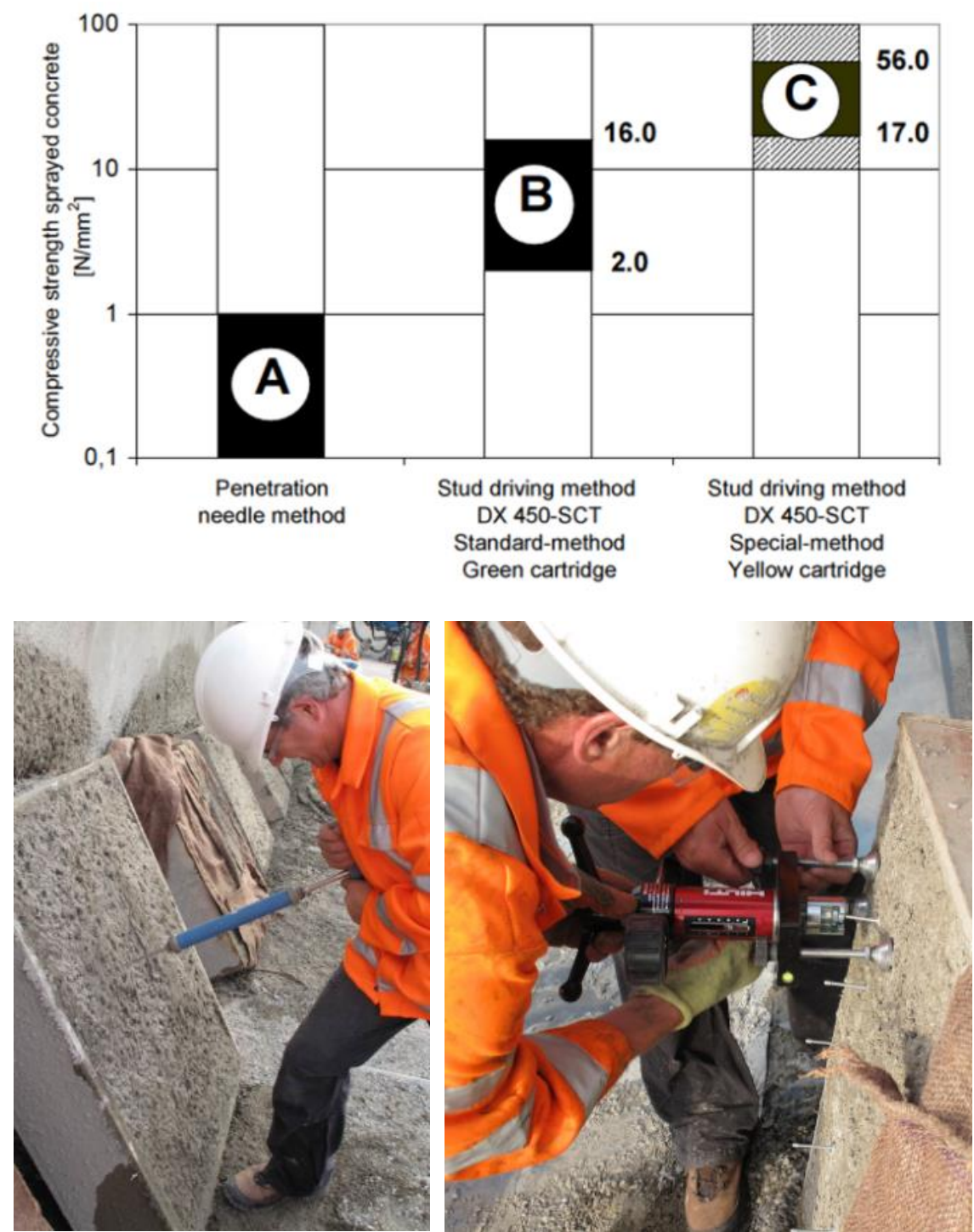

Figure 4 Current best practice for early age shotcrete strength measurement - Proctor penetration needle and Hilti pull-out method

The results are plotted in Figure 5, where the red line represents the early age compressive strength of a typical shotcrete mix for a major soft ground tunnelling project, in this example being Crossrail, London. As can be observed, the early age strength is well-within the $J_{2}$ requirements for the first $4-5$ hrs, and exceeds $J_{3}$ thereafter. This is an attractive sprayed concrete strength development plot for such projects and is being used in a number of mine projects worldwide, and the benefits of the modern mix design with low-water/cement, high-flow workability coupled with active set accelerators assures the strength results. On such tunnelling projects, early age strength testing is routine on each round to ensure the safety of the mining team is not compromised. Testing takes five minutes and is targeted at the time period when the shotcrete should have reached the minimum early age strength requirement. In the case of Crossrail this was typically between 20 and $40 \mathrm{~min}$ after completion of top heading spraying to achieve the minimum project requirement of $0.5 \mathrm{MPa}$.

Requirements for re-entry in the mining industry vary considerably. The assumptions for these existing practices could be based on the following:

- Often the cycle time of other rock support processes are considered and built in to set the re-entry time. 
- Long time periods for re-entry may have been set based on shotcrete technologies that were present during the initial mine development, potentially 20 years ago. Old technologies using higher water/cement mixes, and using old accelerator technology, such as sodium silicates would certainly not have allowed earlier re-entry times less than 5-6 hrs for example.

- Often shift patterns can influence re-entry time requirements.

- The local geology can influence re-entry times, where stronger shotcrete is required to perform efficient rock support.

- The shotcrete quality is considered too variable and early age strengths are not reliable. Further safety is therefore perceived with longer re-entry time requirements.

- A certain degree of 'copy, pasting' of overly conservative practices.

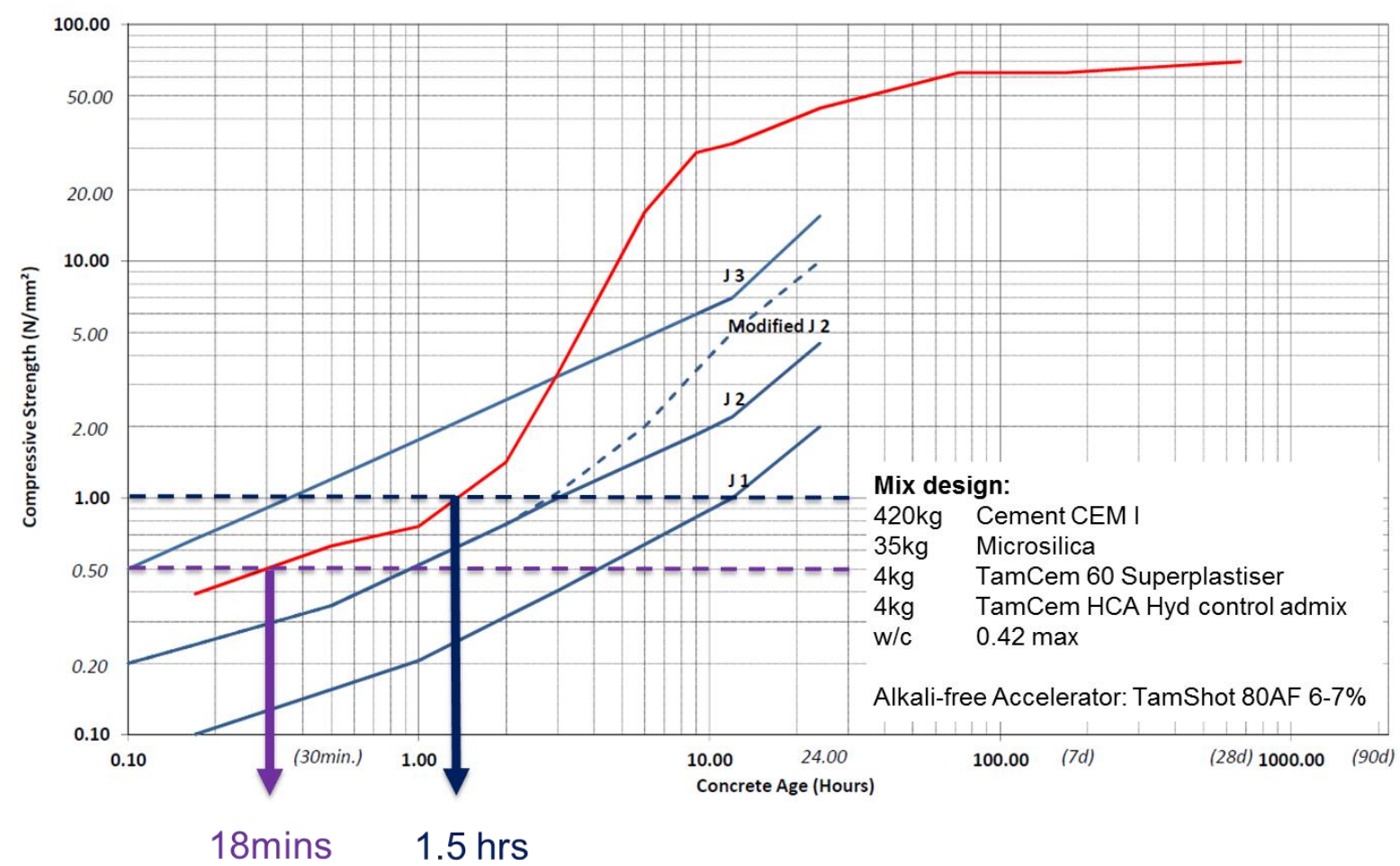

Figure 5 Typical shotcrete early age strength plot for Crossrail, London, showing 0.5 and $1 \mathrm{MPa}$ early re-entry minimal strength requirements often specified for mines

The modern shotcrete performance example given in Figure 5 illustrates a tangible argument for mines to benefit from some technology transfer from the tunnelling industry that would allow safe and significantly faster re-entry times. On Crossrail for example, with $\mathrm{J}_{2}$ specified, with a re-entry requirement of $0.5 \mathrm{MPa}$, the mining team were excavating new ground between 18 and 50 minutes based on their testing. With a mine requiring a minimum re-entry shotcrete strength of $1 \mathrm{MPa}$ for example, a re-entry time of 11.5 hrs may be possible. Obvious production and cycle time benefits are therefore possible.

\subsection{Improved safety practices}

In conventional drill and blast tunnelling using shotcrete ground support, the most significant risks to the mining team are ground collapse at the face or the falling of immature shotcrete sections. In soft ground tunnelling, where shotcrete lining thicknesses can have quite considerable thicknesses between 20 and $40 \mathrm{~cm}$, the impacts of this material falling in large sections can prove fatal. Whilst good practice exists of setting personnel exclusion zones before, during and immediately after shotcreting, the authors believe an industry-wide approach for mines should be an objective. 
As illustrated in Figure 6, Crossrail in the UK developed a Best Practice Guide for the setting and management of shotcrete exclusion zones and this has now become the industry norm in the UK (Crossrail 2014).
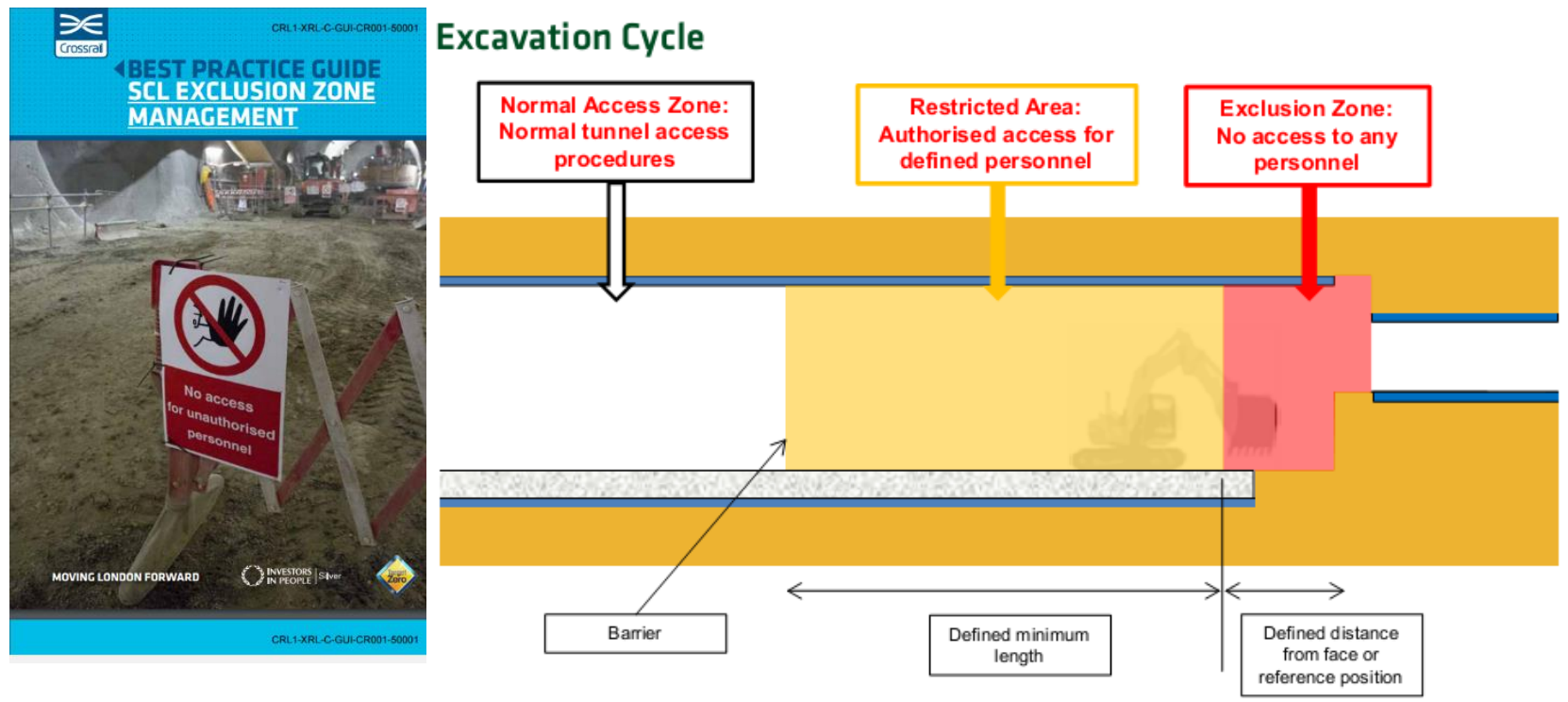

Spraying Cycle

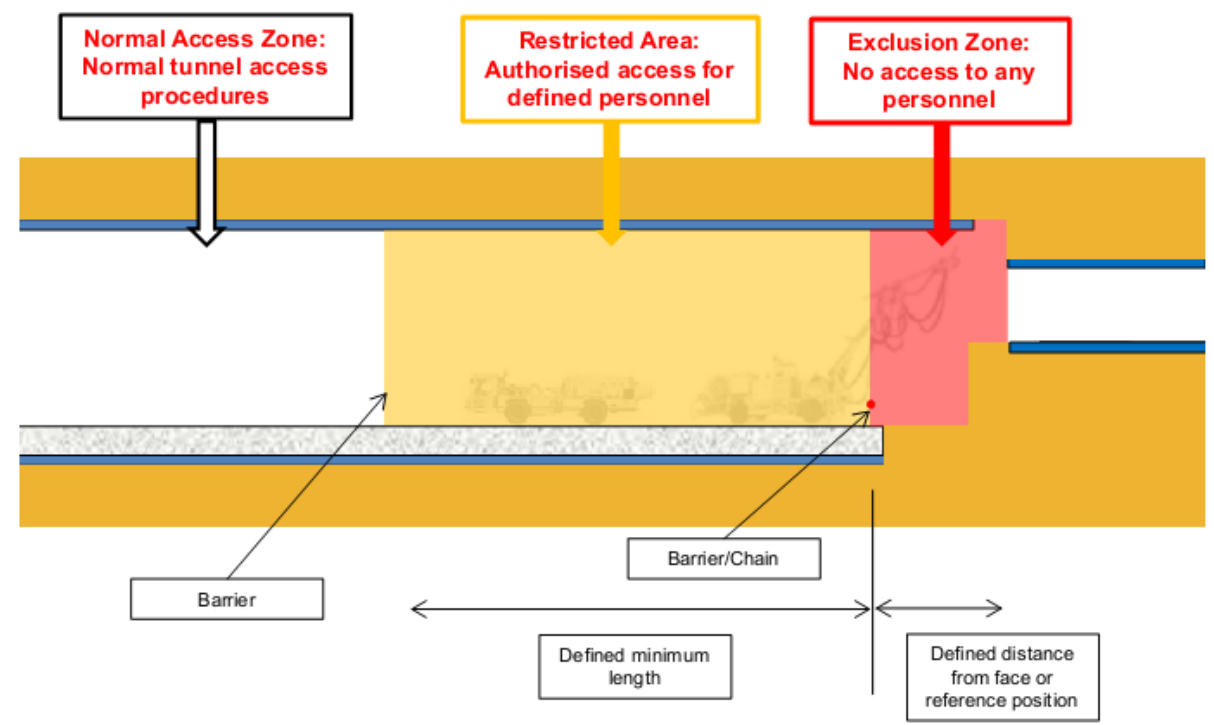

Figure 6 SCL Exclusion Zone Management best practice document produced by Crossrail

To complement measuring early age shotcrete strength, but also to have a more global view of how the rock support in the heading as a whole is developing strength, a system referred to as Strength Monitoring Using Thermal Imaging or SMUTI ${ }^{\mathrm{TM}}$ has been developed at Warwick University in the UK (Ahuja \& Jones 2016). This system shown in Figure 7Figure has been tested and calibrated on Crossrail and, essentially, the higher the hydration temperature measured using hand held thermal cameras, the higher the early age strength. The correlation to penetrometer and Hilti methods is very good and this approach offers the benefits of an immediate global view of the tunnel or mine heading's early age strength development and not just isolated patches or panels tested by penetration needles. 

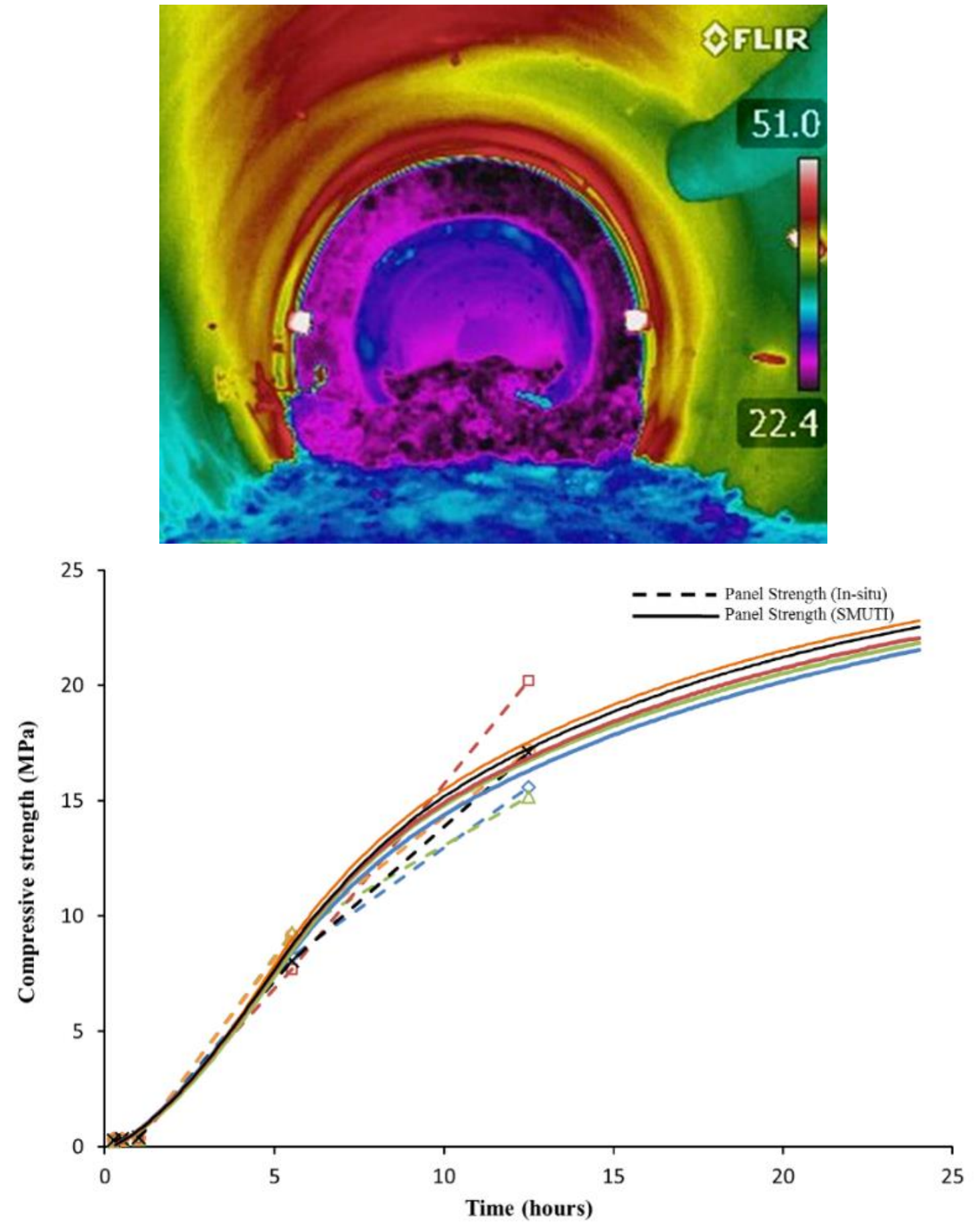

Figure 7 SMUTI technique using thermal imagery to establish global early age strength gain in tunnel headings (Ahuja \& Jones 2016)

\subsubsection{Scanning}

In order to improve safety, and to fulfil requirements in regards to specification of the sprayed concrete lining, scanners to control applied thickness are introduced as part of the sprayed concrete equipment. Currently, developments include the ability to measure and monitor shotcrete thicknesses real-time and transfer data to site office teams via wireless LAN networks as indicated in Figure 8. This is an area that is still under development, and large improvements in terms of simplicity in use, accuracy, and, last but not least, the time taken for scanning shotcrete and excavation profiles to be significantly reduced in the near future, with plots being available underground within minutes, as per the example output illustrated in Figure 9. 


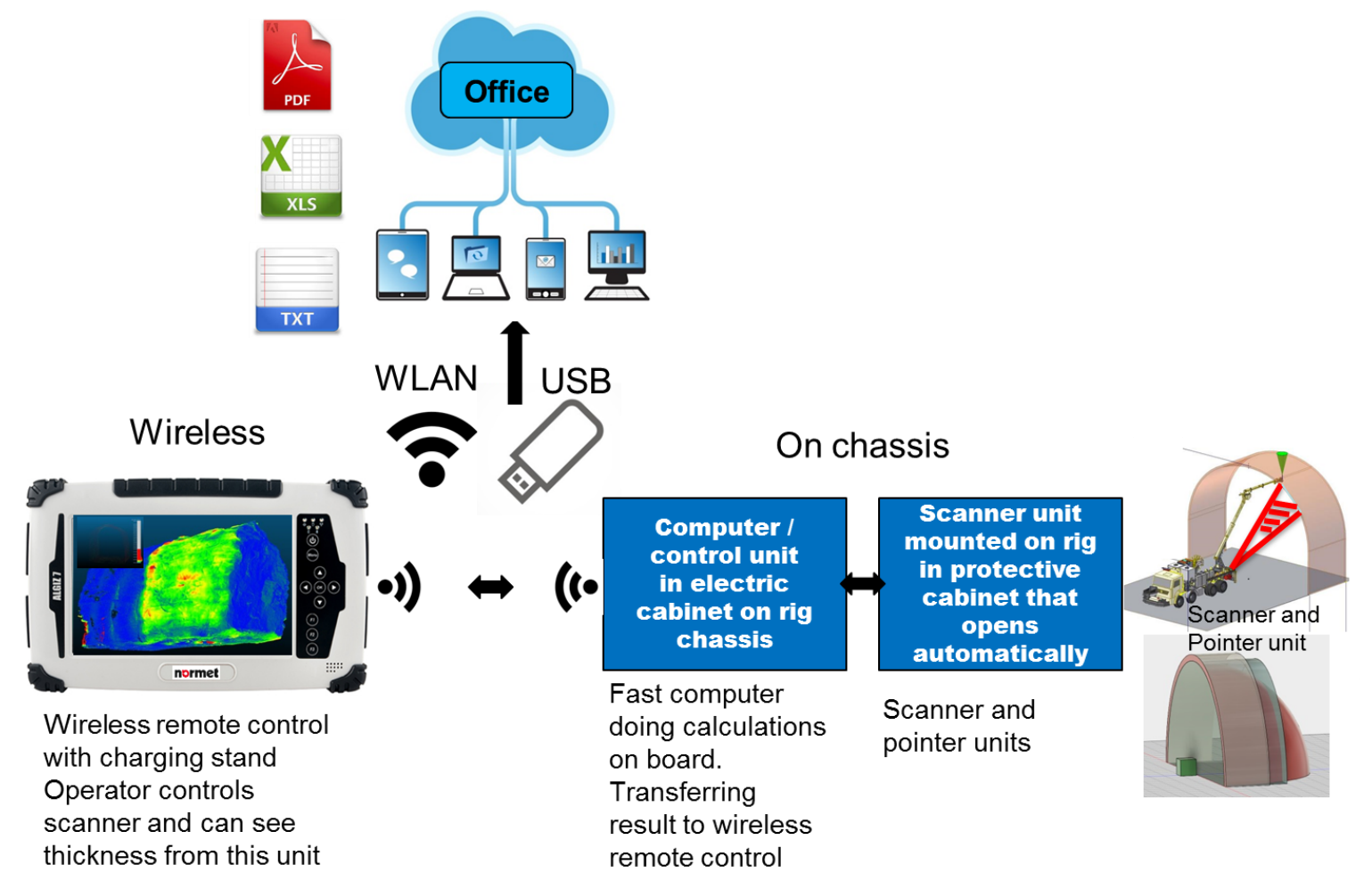

Figure 8 Future excavation and shotcrete scanning development, illustrating interfaces between nozzle operator's real-time remote control display and wireless LAN data transfer between spraying machine and outputs being sent to office for analysis and QC records

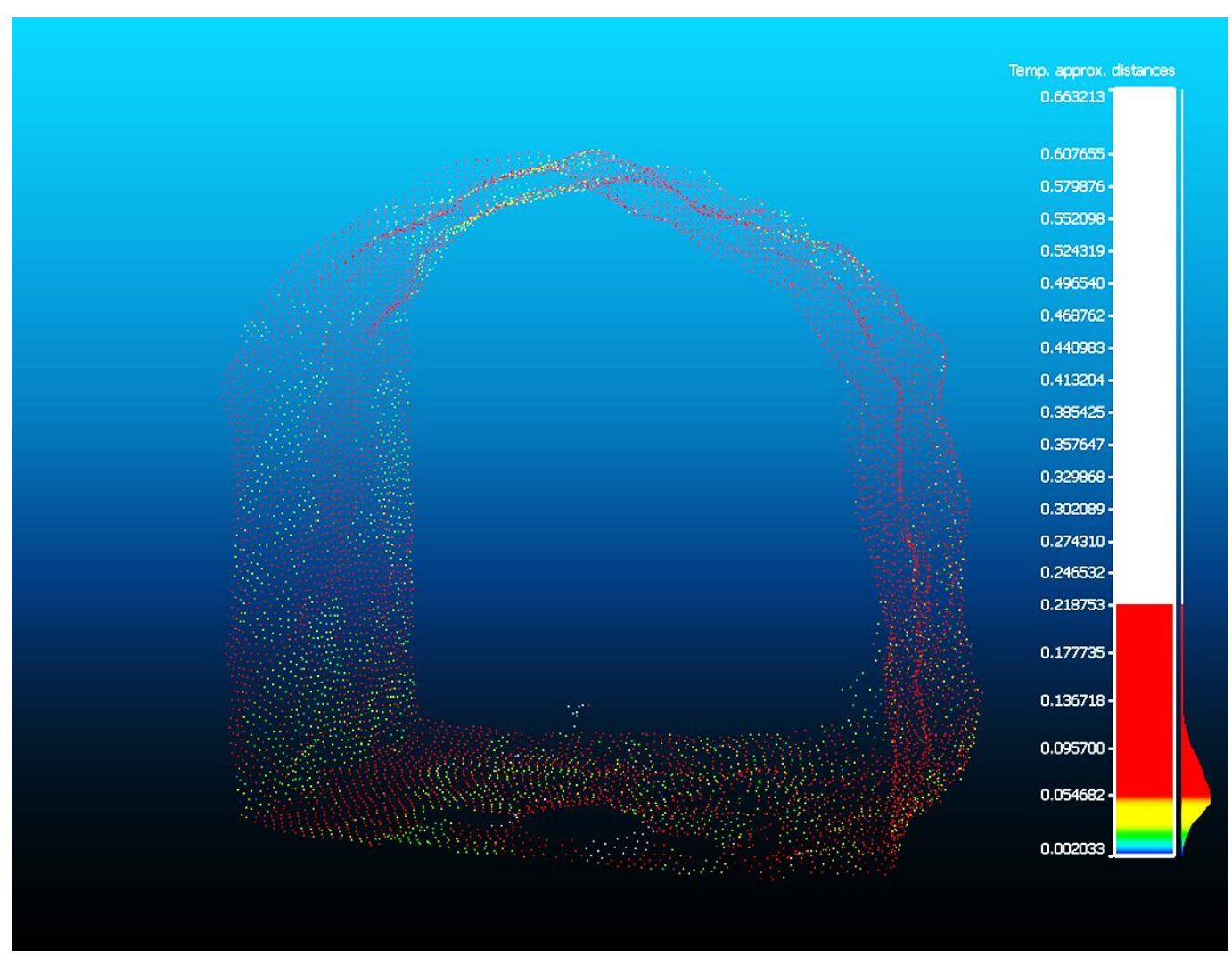

Figure 9 Example of 3D visualisation of excavation profiles and sprayed concrete thickness 


\section{Conclusion}

The threshold for re-entry into a shotcreted heading has reduced over the last 20-30 years to a generalised 1-2 MPa of compressive strength, a key performance indicator of shotcrete toughness. These measurements are taken with a variety of accepted test methods and the consistent reaching of results is made possible by the consistent application of shotcrete fundamentals related to mix design, the correct selection of admixtures and accelerators, fit-for-purpose spraying equipment and expert application procedure.

Recent technology advancements have and continue to contribute to ever earlier, safe re-entries:

- HCA + dormant secondary accelerator in the mix giving superior results at very early age.

- Accelerators which can handle the challenges of blended cements.

- Emergence of alternate fibre materials like basalt.

- Collecting data automatically from the sprayed concrete operation.

Future developments for shotcrete such as low or sulphate-free accelerators and a geopolymer substitute for cement have the potential for bringing stepwise change to the industry.

Finally, the authors can envision a day when we have a global industry standard (subject to local variances) for shotcrete in the underground environment, adopting the best practices across the mining and tunnelling industries.

\section{References}

Ahuja, V \& Jones, B 2016, 'Non-destructive approach for shotcrete lining strength monitoring', Proceedings of the World Tunnel Congress, Society for Mining, Metallurgy, and Exploration, Englewood, pp. 1178-1187.

Bürge, TA, 2001, 'Mode of action of alkali-free sprayed shotcrete accelerators', in ES Bernard (ed.), Shotcrete: Engineering Developments, Proceedings of the International Conference on Engineering Developments in Shotcrete, A.A. Balkema, Rotterdam, pp. 79-85.

British Standards Institution 2006, BS EN 14488-2 Testing Sprayed Concrete - Part 2: Compressive strength of young sprayed concrete, British Standards Institution, London.

Crossrail Ltd 2014, Best Practice Guide - SCL Exclusion Zone Management, Document Ref: CRL1-XRL-C-GUI-CR001-50001, Crossrail Ltd, viewed 23 May 2017, www.britishtunnelling.org.uk

Dimmock, R, Rispin, M \& Knight, B 2003, 'Early re-entry into working faces in mines through modern shotcrete technology', Canadian Institute of Mining, Metallurgy and Petroleum Annual General Meeting 2003, Canadian Institute of Mining, Metallurgy and Petroleum, Westmount.

Lee, ST, Kim, DG \& Jung, HS 2009, 'Sulfate attack of cement matrix containing inorganic alkali-free accelerator', KSCE Journal of Civil Engineering, vol. 13, no. 1, pp. 49-55.

Myrdal, R 1999, 'Modern chemical admixtures for shotcrete', Proceedings of the Third International Symposium on Sprayed Concrete, pp. 373-382.

Myrdal, R 2011, 'Chemical reflections on accelerators for sprayed concrete: past, present and future challenges', Proceedings of the Sixth International Symposium on Sprayed Concrete - Modern Use of Wet Mix Sprayed Concrete for Underground Support, pp. 304-316.

Myrdal, R 2012, 'From alkali-free to sulphate-free: current research on shotcrete accelerators', hand-out document of presentation held at Shotcrete Seminar, Brisbane, 19 June 2012, Concrete Institute of Australia, Perth, 26 p.

Myrdal, R \& Griffith, R 2014a, 'The characteristics and performance of consistence control admixtures for sprayed concrete', Proceedings of the Seventh International Symposium on Sprayed Concrete - Modern Use of Wet Mix Sprayed Concrete for Underground Support, pp. 294-304.

Myrdal, R \& Griffith, R 2014b, 'Admixtures for geopolymer concrete: the performance of accelerating admixtures', Proceedings of the $2^{\text {nd }}$ International Congress on Durability of Concrete, paper no. 24, $11 \mathrm{p}$.

Myrdal, R, Hansen, R \& Tjugum, G 2001, 'A new chemical approach to obtain high early strength in shotcrete', in ES Bernard (ed.), Shotcrete: Engineering Developments, Proceedings of the International Conference on Engineering Developments in Shotcrete, A.A. Balkema, Rotterdam, pp. 193-196.

Ohta, A, Sugiyama, T \& Tanaka, Y 1997, 'Fluidizing mechanism and application of polycarboxylate-based superplasticisers', in VM Malhotra (ed.), Proceedings of the Fifth CANMET/ACI International Conference on Superplasticisers and Other Chemical Admixtures in Concrete, paper no. SP 173-19, pp. 359-378.

Paglia, C, Wombacher, F \& Böhni, H 2003, 'The influence of alkali-free and alkaline shotcrete accelerators within cement systems. Influence of the temperature on the sulphate attack mechanisms and damage', Cement and Concrete Research, vol. 33, pp. 387-395. 
Prudêncio Jr, LR 1998, 'Accelerating admixtures for shotcrete', Cement and Concrete Composites, vol. 20, pp. 213-219.

Rispin, M, Knight, B \& Dimmock, R 2003 'Early re-entry into working faces in mines through modern shotcrete technology - part II'; Proceedings of the Canadian Institute of Mining, Mine Operators Conference 2003, Canadian Institute of Mining, Metallurgy and Petroleum, Westmount.

Rispin, M, Kleven, OB, Robbins, M, Dimmock, R \& Skogseth, T 2013, 'Development in block cave mines', Proceedings of the Safe, Rapid Development Conference 2013, International Mining, London.

Rispin, M, Melbye, T \& Kraft, R 2009, 'Sprayed concrete systems for present and future: logistics and application', Mining Magazine Technology Conference 2009, Mining Magazine, London.

Rixom, R \& Mailvaganam, N 1999, 'Chapter 5', Chemical Admixtures for Concrete, E\&FN Spon, London, pp. $252-265$. 